\title{
Agronomic
} Journal jê

\section{USO DE BIOAGENTES NA SUPRESSÃO DA Macrophomina phaseolina NA CULTURA DO FEIJOEIRO COMUM}

\author{
USE OF BIOAGENTS IN THE SUPPRESSION OF Macrophomina phaseolina IN THE COMMON BEAN \\ CULTURE
}

\author{
Geana Jesus Caixeta ${ }^{1}$; Lucas Marquezan Nascimento $^{2}$; Marta Cristina Corsi de Filippi ${ }^{3}$; Fábio José \\ Gonçalves"; Alan Carlos Alves de Souza ${ }^{*}$
}

${ }^{1}$ Engenheira Agrônoma. Universidade Evangélica de Goiás - UniEVANGÉLICA. geanajemw2011@hotmail.com.

${ }^{2}$ Engenheiro Agrônomo. Universidade Evangélica de Goiás - UniEVANGÉLICA, curso de Agronomia.mznlucas@outlook.com.

${ }^{3}$ Engenheira Agrônoma. Embrapa Arroz e Feijão. cristina.filippi@embrapa.br.

${ }^{4}$ Biólogo. Laboratório Agrolab. agrolabsementes@gmail.com.

${ }^{5 *}$ Engenheiro Agrônomo. Universidade Evangélica de Goiás - UniEVANGÉLICA, curso de Agronomia.

alancarlosagro@gmail.com.Autor correspondente.

\begin{tabular}{l} 
Info \\
\hline Recebido: 05/2021 \\
Publicado: 06/2021 \\
ISSN: 2595-6906 \\
DOI: 10.37951/2595-6906.2021v5i1.6881 \\
\hline Palavras-Chave \\
Controle biológico, Fungos, \\
Rizobactérias, Feijão, Promoção de \\
Crescimento. \\
Keywords: \\
Biological control, Fungi, Rhizobacteria, \\
Beans, Growth Promotion.
\end{tabular}

\begin{abstract}
Resumo
A Macrophomina phaseolina causa a doença podridão-cinzenta-docaule na cultura do feijoeiro e leva a perdas significativas do grão devido às dificuldades para o controle. Diante disso, o objetivo deste trabalho foi avaliar o efeito do uso de Trichoderma e de rizobactérias como bioagentes na supressão da doença na cultura do feijoeiro comum. 0 experimento foi realizado em condição de telado e adotouse o delineamento em blocos inteiramente casualizados. Foram realizados seis tratamentos com oito repetições. Os tratamentos consistiram em: T1- Testemunha; T2 - Pseudomonas fluorescens; T3 - Burkholderia pyrrocinia; T4 - Bacillus sp.; T5 - Trichodermil $1306 \AA$ e T6 - Rancona T®. Os tratamentos foram aplicados via semente e pulverização foliar aos 14 e 21 dias após o plantio. 0 fitopatógeno Macrophomina phaseolina foi inoculado aos 21 dias após o plantio, utilizando o método de palitos-de-dente. A avaliação da severidade da doença e da área abaixo da curva de progresso da doença (AACPD) foi realizada aos 1, 2, 4 e 8 dias após a inoculação,
\end{abstract} por meio de uma escala de notas descritivas. A avaliação da promoção de crescimento foi realizada aos 21 dias após o plantio. As plantas de feijoeiro que tiveram o tratamento de sementes e a pulverização foliar com as rizobactérias P. fluorescens e Bacillus sp. se sobressaíram significativamente, aumentando a biomassa da parte aérea em 46,73\% e 41,43\%, respectivamente, em comparação a testemunha. As plantas tratadas via sementes e via pulverização foliar com a rizobactéria Bacillus sp. apresentaram menor índice de severidade da doença, com supressão de 51,67\% em relação a testemunha. Segundo AACPD, o tratamento que apresentou menor área com presença de plantas doentes foi o tratamento com a bactéria Bacillus sp. com 34,58 \%. De acordo com os resultados obtidos, a utilização dos bioagentes Bacillus sp. e Trichoderma harzianum se mostraram eficientes na supressão da Macrophomina phaseolina na cultura do feijoeiro comum. A utilização de Pseudomonas fluorescens e o Bacillus sp. são eficientes na promoção de crescimento de biomassa de parte aérea. 


\section{INTRODUÇÃO}

Sendo uma das principais culturas produzidas no Brasil e constituindo a base da alimentação humana, o feijoeiro teve origem na América Central (MARTINS, 2015) e foi largamente distribuído em todo o mundo (SILVA; COSTA, 2003). Sua importância socioeconômica vem principalmente da agricultura familiar, devido a geração de renda, além de ter grande destaque nutritivo na dieta da população, por ser imprescindível fonte de proteína (VAZ, 2020).

A cultura do feijoeiro apresenta sua implantação em três épocas diferentes, dependendo da região. Sendo a primeira safra com a época de plantio entre agosto e novembro, a segunda safra com época de plantio de dezembro a março, e a terceira safra com época de plantio entre abril e julho (VAZ, 2020).

Estima-se que a área plantada no Brasil seja de 2.964,9 mil ha na safra 2019/2020, para a cultura do feijão nas três safras. A estimativa para as três safras, é que se obtenha uma produtividade de $1.059 \mathrm{~kg} \mathrm{ha}^{-1}$, onde o maior produtor de feijão nacional seja o Estado do Paraná, produzindo 763,8 mil t, ficando o Estado de Goiás em quarto lugar, com uma produção de 302,0 mil $\mathrm{t}$ (CONAB, 2020a).

No Brasil, a área de primeira safra do feijão vem sendo reduzida ao longo dos anos, isso devido a competição com o milho (Zea mays L.) e a soja (Glycine max L.), e também da época de sua colheita acabar acontecendo no período de chuva, o que acaba ocasionando grandes problemas na qualidade do produto (CONAB, 2020a). As pragas e doenças fazem parte desses problemas, devido encontrarem seu hospedeiro grande parte do ano, favorecendo sua multiplicação (ADAMSKI, 2019).

As principais patologias que ocorre no feijoeiro são causadas por vírus, nematoides, bactérias e por fungos. Dentre as principais tem-se o Mosaico-dourado (Bean Golden Mosaic Virus), o Crestamento-bacterianocomum (Xanthomonas axonopodis pv. phaseol), as
Podridões radicular de rizoctonia e seca (Rhiroctonia solani e Fusarium solani f. sp. phaseoli respectivamente), o Mofo branco (Sclerotinia sclerotiorum), a Antracnose (Colletotrichum lindemuthianum) e a Podridão-cinzenta-docaule (Macrophomina phaseolina), sendo esta a principal doença da cultura do feijoeiro (PAULA JUNIOR et al., 2008).

A Macrophomina phaseolina é um fungo habitante do solo que pertence à família Botryosphaeriaceae, ordem Botryosphaeriales, da classe Dothideomycetes e filo Ascomycota (CROUS et al., 2006). Este fungo causa seca e morte de plântulas, cancro e lesões no caule de coloração cinzentas, ocorrendo epidemias da doença quando em temperaturas altas e baixa umidade (ATHAYDE SOBRINHO, 2004). O controle é muito difícil pelo fato da existência de estruturas de resistências, que aumentam sua sobrevivência nas mais adversas condições ambientais, e por quase não existir no Ministério da Agricultura, Pecuária e Abastecimento (MAPA) produtos registrados para seu controle no feijão. Tais fatores acabam favorecendo o uso ilegal de fungicidas e o aumento do uso indiscriminado dos produtos químicos, o que tem estimulado a procura por controles alternativos (DIAS et al., 2019).

A utilização de microrganismos vivos no biocontrole de patógeno é a principal alternativa para eliminar ou reduzir a utilização de agrotóxicos no controle de fitopatógenos. A grande quantidade de microrganismos, ligada a suas ações antagônicas tornam-se importante ferramenta de controle biológico para o manejo integrado da doença (VIEIRA et al., 2017). Diante do exposto, o trabalho teve como objetivo avaliar o efeito do uso de Trichoderma e de rizobactérias como bioagentes na supressão da Macrophomina phaseolina na cultura do feijoeiro comum.

\section{MATERIAL E MÉTODOS}

\subsection{Delineamento experimental}


O experimento foi realizado na Estação Experimental da EMATER, que se localiza na cidade de Anápolis - GO, próximo a GO 060, Km 121, na zona rural, com latitude $16^{\circ} 20^{\prime} 12.614$ ' S, longitude $48^{\circ}$ 53’ 13.101" O e altitude média de $1.051 \mathrm{~m}$, o qual foi feito em condições de casa de vegetação. O local da instalação do experimento possui características climáticas tropicais, com temperaturas mínima de $18^{\circ} \mathrm{C}$ e máxima de $28^{\circ} \mathrm{C}$ e precipitação pluviométrica média anual de $1.450 \mathrm{~mm}$.

O ensaio foi conduzido em delineamento em blocos inteiramente casualizados, em condição de telado, recebendo seis tratamentos com oito repetições (sendo quatro repetições para avalição da doença e quatro repetições para avaliação da promoção de crescimento). Foram utilizados o produto comercial Trichodermil $1306^{\circledR} \quad$ (Trichoderma harzianum, cepa ESALQ-1306 $48 \mathrm{~g} \mathrm{~L}^{-1}$ ), Rancona $\mathrm{T}^{\circledR}$ (Ipconazol $10 \mathrm{~g} \mathrm{~L}$ 1 e Tiram $350 \mathrm{~g} \mathrm{~L}^{-1}$ ) e as rizobactérias Pseudomonas fluorescens BRM 32112, Burkholderia pyrrocinia BRM 32113, pertencentes a Coleção de Microrganismos Multifuncionais da Embrapa Arroz e Feijão e, Bacillus sp. AGL 21, pertencente a Coleção de Isolados Microbianos do Laboratório Agrolab. Os tratamentos consistiram em: T1- Testemunha; T2 - P. fluorescens; T3 - B. pyrrocinia; T4 - Bacillus sp.; T5 - Trichodermil $1306^{\circledR}$ e T6 - Rancona $\mathrm{T}^{\circledR}$. O ensaio foi realizado em copos plásticos (400 mL), com furos no fundo e contendo o substrato comercial Ouro Negro ${ }^{\circledR}$ esterilizado (mistura de esterco de gado e de aves, húmus de minhoca, bokashi e casca de pinus), onde foram semeadas três sementes por copo. A cultivar de feijão utilizada foi a BRS FC 104, feijão carioca.

\subsection{Aplicação dos tratamentos}

A aplicação dos tratamentos foi realizada via tratamento de sementes, momentos antes do plantio, e via pulverização foliar, a qual foi feita aos 14 e aos 21 dias após o plantio. Para a realização do tratamento das sementes e da pulverização foliar com as bactérias, foi produzido uma suspensão, onde os microrganismos foram separadamente cultivados em placa de Petri contendo o meio de cultura Batata Dextrose Agar (BDA), e posteriormente, as placas foram inseridas em uma câmara de crescimento BOD por 48 h, em aproximadamente $28{ }^{\circ} \mathrm{C}$. Depois de passar o tempo necessário, as placas foram lavadas com água destilada com o auxílio de uma alça de Drigalski, elaborando-se a suspensão bacteriana (KADO; HESKETT', 1970, citado por COSTAMILAN et al., 2017).

As suspensões bacterianas foram padronizadas com a colaboração de um espectrofotômetro e ajustadas com comprimento de onda de 540 nanômetros e 0,5 de absorbância, obtendo a concentração de $1 \times 10^{8} \mathrm{UFC} \mathrm{mL}^{-1}$ com o auxílio de uma câmara de Neubauer (FILIPPI et al., 2011). Com a suspensão das bactérias prontas, a dosagem adotada para realizar o tratamento das sementes, foi de $300 \mathrm{~mL}$ para $50 \mathrm{Kg}^{-1}$ de sementes, e para a pulverização foliar foi de $1 \mathrm{~L} \mathrm{ha}^{-1}$.

Para a utilização do produto biológico Trichodermil $1306^{\circledR}$, foi utilizado a dosagem de $200 \mathrm{~g}$ para $100 \mathrm{~kg}^{-1}$ de sementes no tratamento de sementes, com a concentração de $2 \times 10^{9}$ conídios $\mathrm{mL}^{-1}$, e não foi realizado a pulverização foliar na cultura. Para o produto comercial Rancona $T^{\circledR}$, foi adotado a dosagem de $150 \mathrm{~mL}$ para $50 \mathrm{Kg}^{-1}$ de sementes no tratamento de sementes, e não foi realizado a pulverização foliar. Os tratamentos descritos acima estão seguindo as recomendações em bula pelos fabricantes para cultura do feijão. No tratamento das sementes, foram utilizados sacos plásticos, onde as sementes eram adicionadas juntamente com os devidos tratamentos, agitando-os até obter homogeneidade completa das sementes com os tratamentos.

\subsection{Inoculação do patógeno e avaliação da}

\section{doença}


Para a inoculação do patógeno nas plântulas de feijoeiro foi utilizado o isolado fúngico de Macrophomina phaseolina, proveniente da Coleção de Isolados Microbianos do Laboratório Agrolab. Inicialmente foi levado à fervura cerca de 100 palitos-de-dente da madeira pinus, com a intenção de eliminar sua resina, e posteriormente foram levados a secagem. Em seguida foram cortados em $1 / 2$ de seu tamanho normal mantendo uma ponta em uma de suas extremidades (TESSO; EJETA, 2011).

Após cortados os palitos foram colocados nas placas de Petri, em uma quantidade de cerca de 50 palitos-de-dente por placa de Petri, os quais foram esterilizados em autoclave por $30 \mathrm{~min}$ a $120^{\circ} \mathrm{C}$ e $1 \mathrm{~atm}$. O meio de cultura BDA foi adicionado na placa já contendo os palitos, sendo distribuído em uma quantidade em que o palito na posição vertical fique fora do meio, cerca de 3 a $4 \mathrm{~mm}$ na extremidade apontada. Após o resfriamento o fungo foi repicado sobre o meio de cultura e os palitos, os quais foram levados a incubação a uma temperatura de $30{ }^{\circ} \mathrm{C}$ durante o prazo de 10 dias, até que a placa fosse totalmente colonizada pelo fungo (TESSO; EJETA, 2011).

Ao completar 21 dias após o plantio foi feita a inoculação das plantas com o isolado fúngico da $M$. phaseolina, espetando a extremidade afiada de dois palitos por planta em cerca de $1 \mathrm{~cm}$ abaixo do nó cotiledonar, sendo dispostos em lados opostos na planta, e com o distanciamento de cerca de $1 \mathrm{~cm}$ entre si. A inserção do palito na haste foi realizada sem que a atravesse totalmente, finalizando a inoculação do patógeno. As plantas foram mantidas em temperatura ambiente e sob regime hídrico com irrigação a cada dois dias (TESSO; EJETA, 2011).

Para a avaliação da severidade da doença e da Área Abaixo da Curva de Progresso da Doença (AACPD), foi realizado avaliações aos 1, 2, 4 e 8 dias após a inoculação do patógeno, na qual foi empregada

uma escala de notas adaptada de Abawi; Pastor Corrales (1990). Para calcular a AACPD, utilizou-se dos dados obtidos da severidade, conforme metodologia de Campbell; Madden (1990).

\subsection{Avaliação da promoção de crescimento}

Aos 21 dias após o plantio foi realizado a avaliação de crescimento das plântulas de feijoeiro, com o auxílio de uma régua métrica. As plantas foram medidas avaliando o tamanho da parte radicular e da parte aérea $(\mathrm{cm})$. Após as medições e com uma tesoura, tais partes medidas foram separadas, acondicionadas em sacos de papel e levadas para a estufa, onde ficaram cerca de $72 \mathrm{~h}$ em uma temperatura de $60{ }^{\circ} \mathrm{C}$ para a secagem. Após secas, as plantas foram pesadas em uma balança de precisão, para a determinação de biomassa (g) de cada uma das amostras.

\subsection{Análise estatística}

Todos os dados obtidos foram submetidos a análise de variância e teste de Tukey a $5 \%$ de significância. Para tal foi utilizado o software SPSS, versão 21.

\section{RESULTADOS E DISCUSSÃO}

\subsection{Biomassa e promoção de crescimento}

Observou-se diferença estatística entre os diferentes tratamentos testados na biomassa de parte aérea. Com a avaliação de biomassa da parte aérea, os resultados obtidos evidenciaram que as plantas de feijoeiro comum que tiveram o tratamento das sementes e a pulverização foliar com as rizobactérias Psendomonas fluorescens e Bacillus sp. se sobressaíram significativamente, se revelando eficientes no aumento da biomassa, aumentando-a em 46,73\% e 41,43\%, respectivamente, em relação a biomassa da testemunha (Tabela 1). 
TABELA 1- Avaliação do comprimento e da biomassa da parte aérea e da raiz, realizadas no vigésimo primeiro dia após o plantio em plantas de feijoeiro comum, em condição de telado. Teste de Tukey a 5\% de significância. Anápolis, Goiás, 2020.

\begin{tabular}{ccccc}
\hline \multirow{2}{*}{ Tratamento } & \multicolumn{2}{c}{ Comprimento $(\mathrm{cm})$} & \multicolumn{2}{c}{ Biomassa $(\mathrm{g})$} \\
\cline { 2 - 5 } & Raiz & Parte Aérea & Raiz & Parte Aérea \\
\hline Testemunha & $17,08 \mathrm{a}$ & $11,00 \mathrm{a}$ & $0,530 \mathrm{a}$ & $0,659 \mathrm{~b}$ \\
Pseudomonas fluorescens & $19,99 \mathrm{a}$ & $11,21 \mathrm{a}$ & $0,578 \mathrm{a}$ & $0,967 \mathrm{a}$ \\
Burkholderia pyrrocinia & $18,67 \mathrm{a}$ & $12,23 \mathrm{a}$ & $0,684 \mathrm{a}$ & $0,846 \mathrm{ab}$ \\
Bacillus sp. & $19,06 \mathrm{a}$ & $12,96 \mathrm{a}$ & $0,710 \mathrm{a}$ & $0,932 \mathrm{a}$ \\
Trichodermil ${ }^{\circledR}$ & $18,56 \mathrm{a}$ & $12,28 \mathrm{a}$ & $0,684 \mathrm{a}$ & $0,874 \mathrm{ab}$ \\
Rancona T® & $18,51 \mathrm{a}$ & $11,51 \mathrm{a}$ & $0,534 \mathrm{a}$ & $0,743 \mathrm{ab}$ \\
\hline $\mathrm{CV}(\%)$ & 15,07 & 19,43 & 16,31 & 10,91 \\
\hline
\end{tabular}

*Médias seguidas pelas mesmas letras não diferem entre si pelo teste de Tukey ( $\mathrm{P}>5 \%)$.

Em relação aos dados da biomassa das plantas sobre a raiz não houve significância, porém, o tratamento com o Bacillus sp. obteve a maior média. Não houve significância entre os tratamentos de avaliação da promoção de crescimento da raiz e da parte aérea das plantas, contudo, as maiores médias foram obtidas pelos tratamentos com a P. fluorescens e o Bacillus sp., respectivamente (Tabela 1).

Em experimento conduzido em condições de campo, Cerqueira et al. (2015) utilizando sementes de feijoeiro comum microbiolizadas com suspensões bacterianas do gênero Bacillus, obtiveram contribuição significante para o incremento da biomassa da parte aérea, da biomassa fresca da parte aérea e da raiz e no número de sementes, porém, não foi especificado a porcentagem de aumento da biomassa. Em conclusões semelhantes, após estudos sobre a microbiolização na qualidade de sementes e crescimento de plantas de feijão-caupi, Sá (2019) concluiu a promoção do aumento da massa seca da parte aérea de 61,88\% através da utilização de Bacillus subtilis, e da raiz de $57,89 \%$ e 28,94\% por meio da utilização de Trichoderma sp. e Bacillus sp. respectivamente, em condição de casa de vegetação. Araújo et al. (2012), utilizando sementes de feijão-caupi inoculadas com rizobactérias promotoras de crescimento, em trabalho conduzido em campo, na avaliação de produção de massa seca da parte aérea de feijão-caupi, concluiu que a utilização de Bacillus subtilis inoculado sozinho contribuiu para o aumento da produção de massa seca na leguminosa, aumentando em 52,43\% a produção de biomassa. Assim, esses trabalhos corroboram com os resultados obtidos.

A atuação das Rizobactérias Promotoras de Crescimento de Plantas (RPCP's) no desenvolvimento e na promoção de crescimento das plantas podem ser notadas de diversas maneiras. As mais notáveis são a fixação biológica de nitrogênio, a produção de hormônios como o etileno, giberelinas, auxinas e citocininas, o aumento da atividade do nitrato redutase quando desenvolvem endofiticamente nas culturas, a solubilização do fosfato, além de trabalharem como biocontroladores de pragas e patógenos. Acredita-se que o trabalho agrupado de todos esses mecanismos é o responsável pela ocorrência da promoção de crescimento em diversas plantas (FERREIRA, 2018a).

As bactérias do gênero Pseudomonas podem ser encontradas na água, solo, folhagens e sedimentos, destacando-se em razão da imensa versatilidade nutricional na produção agrícola, pela gigantesca capacidade de colonização radicular e sua habilidade de crescimento em grande variedade de ambientes (BARBORA, et al., 2017). As bactérias Bacillus spp. são formadoras de endósporos, que proporciona resistência 
e garantia de sobrevivência em condições diversas de ambiente, logo, a facilidade de colonização é maior (FERREIRA, 2018b).

\subsection{Supressão da doença}

Constatou-se diferença estatística entre os tratamentos testados. As plantas tratadas via sementes e via pulverização foliar com a rizobactéria Bacillus sp. obtiveram os melhores resultados, apresentando menor índice de severidade da doença, com supressão de $51,67 \%$ em relação a testemunha, seguido do tratamento contendo sementes tratadas com Trichodermil® (Trichoderma harzianum), apresentando $11,66 \%$ de supressão da doença em relação a testemunha (Tabela 2).

TABELA 2. Avaliação da severidade da podridão cinzenta do caule (Macrophomina phaseolina) em plantas de feijoeiro comum em diferentes tratamentos realizados em condição de telado. Teste de Tukey a 5\% de significância. Anápolis, Goiás, 2020.

\begin{tabular}{cc} 
Tratamento & Severidade $(\%)$ \\
\hline Testemunha & $75,00 \mathrm{~b}$ \\
Pseudomonas fluorescens & $75,00 \mathrm{~b}$ \\
Burkholderia pyrrocinia & $75,00 \mathrm{~b}$ \\
Bacillus sp. & $36,25 \mathrm{a}$ \\
Trichodermil® & $66,67 \mathrm{~b}$ \\
Rancona T® & $75,00 \mathrm{~b}$ \\
\hline CV $(\%)$ & 10,31 \\
\hline
\end{tabular}

*Médias seguidas pelas mesmas letras não diferem entre si pelo teste de Tukey $(\mathrm{P}>5 \%)$.

Segundo a Área Abaixo da Curva de Progresso da Doença (Figura 1A), o tratamento que se destacou apresentando menor área com presença de plantas doentes, foi o tratamento com a bactéria Bacillus sp., seguido do tratamento com Trichodermil ${ }$ (Trichoderma harz̧ianum), apresentando supressão de 65,42\% e $10,77 \%$, respectivamente. Os primeiros sintomas da doença puderam ser observados a partir do segundo dia de avaliação, realizado dois dias após a inoculação do patógeno. O aumento da severidade da doença foi agressivo na testemunha e nos tratamentos com $P$. fluorescens, B. pyrrocinia e com o produto químico Rancona T®, porém, nos tratamentos com Bacillus sp. e $T$. harzianum o fungo não se desenvolveu com a mesma agressividade, mesmo apresentando ambiente propício a seu desenvolvimento, com temperaturas altas e baixa umidade devido a irrigação controlada.
Os resultados da aplicação dos tratamentos podem ser observados no proceder da doença ao decorrer dos 8 dias após a inoculação do patógeno (Figura 1B), onde a partir do $2^{\circ}$ d.a.i. (dias após a inoculação), o tratamento com Bacillus sp. se diferencia dos demais tratamentos, manifestando menor severidade da doença. A evolução da severidade da doença nos demais tratamentos foram constantes, com progressiva evolução até o $8^{\circ}$ d.a.i. (Figura 1B).

A severidade da doença pode ser observada na Figura 2, onde da esquerda para a direita, são observados os resultados da última avaliação, que acarretou em morte das plantas em Testemunha, $P$. fluorescens, B. pyrrocinia e Rancona $\mathrm{T}^{\circledR}$, além, dos tratamentos Bacillus sp., Trichodermil ${ }^{\circledR}$, que apresentavam plantas ainda vivas e com o mínimo de severidade da doença, comprovando a potencial supressão do patógeno. 

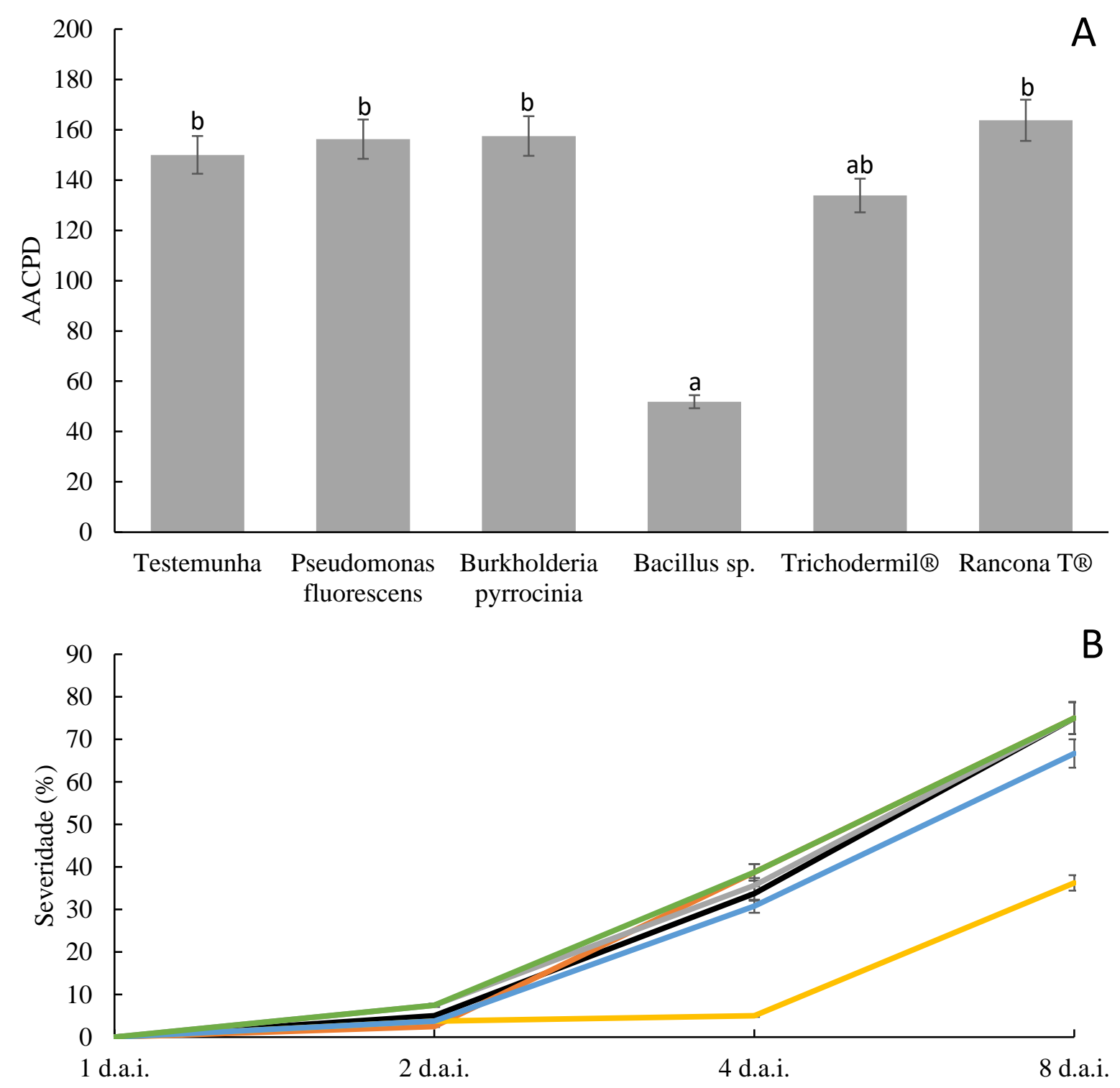

$\begin{array}{ll}\text { Testemunha } & \text { Pseudomonas fluorescens } \\ \text { Bacillus sp. } & \text { Trichodermil }{ }^{\circledR} \quad \text { Burkholderia pyrrocinia }\end{array}$

FIGURA 1 - A: Área Abaixo da Curva de Progresso da Doença (AACPD) e; B: Progresso da severidade da podridão cinzenta do caule (Macrophomina phaseolina) aos 1, 2, 4 e 8 dias após a inoculação (d.a.i.) do patógeno em plantas de feijoeiro comum (Phaseolus vulgaris), submetidas a diferentes tratamentos. Teste de Tukey a 5\% de significância. Anápolis, Goiás, 2020. 


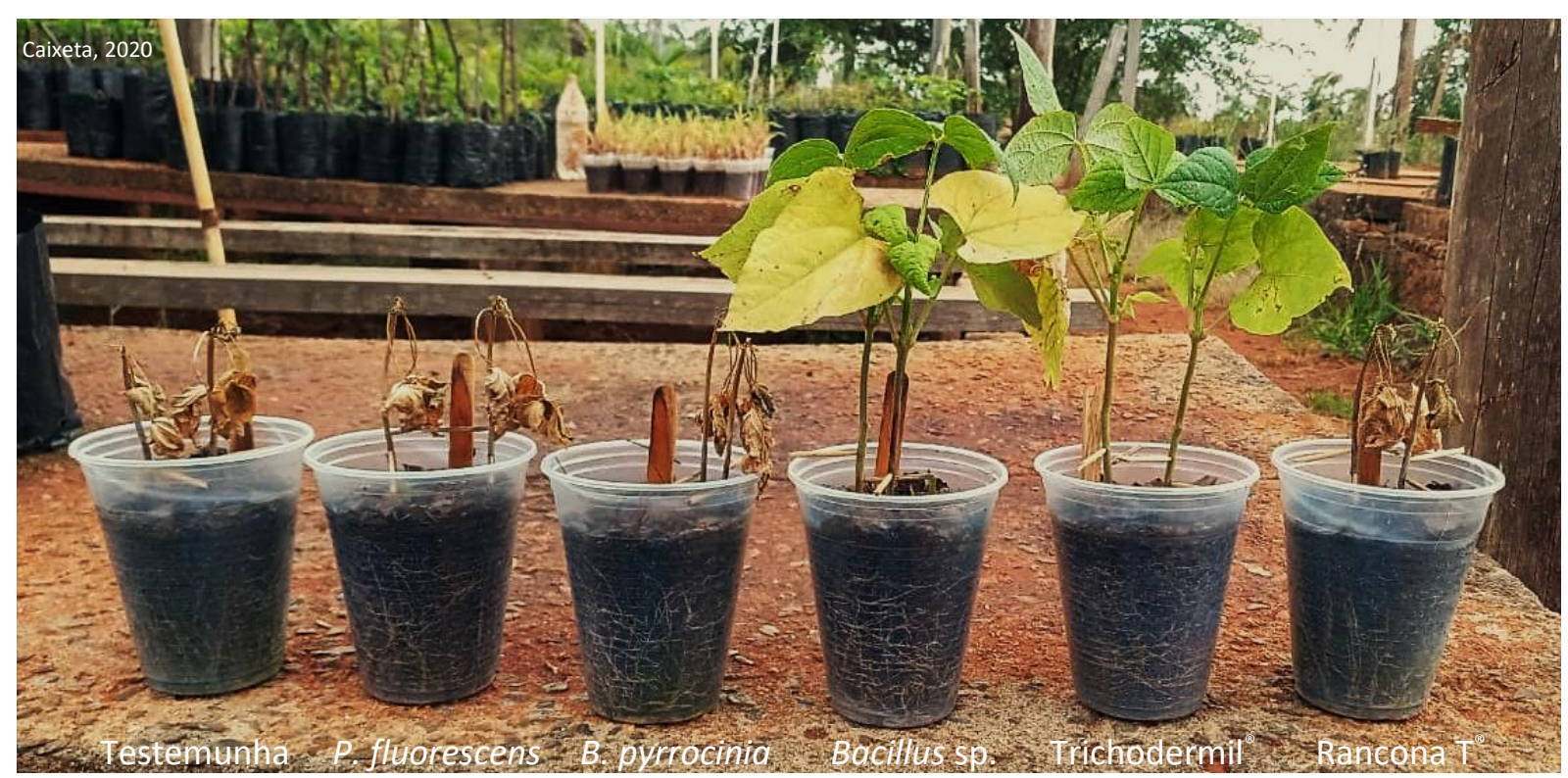

FIGURA 2 - Aspectos gerais da avaliação da severidade aos 8 dias após a inoculação da Macrophomina phaseolina nos diferentes tratamentos utilizados na cultura do feijoeiro comum. Anápolis, Goiás, 2020.

Não se tem conhecimento de estudos in vivo do controle biológico da $M$. phaseolina na cultura do feijoeiro, porém, dentre os trabalhos encontrados, a grande maioria são realizadas em laboratório, com testes in vitro. Vieira et al. (2016), em laboratório, utilizando de placas de Petri de $9 \mathrm{~cm}$, avaliou o potencial efeito fungicida de B. subtilis contra Fusarium spp., $M$. phaseolina e R. solani, os quais são patógenos radiculares da cultura do feijoeiro, onde pode concluir que a relação direta do bioagente com os fungos M. phaseolina e $R$. solani resultaram no impedimento do crescimento micelial de 100\% em comparação com suas respectivas testemunhas.

Com trabalho desenvolvido in vitro, Silva et al. (2013) avaliaram a inibição do crescimento de $M$. phaseolina por isolados de Bacillus (retirados ao acaso de amostras de nabo, trigo, aveia, tremoço e milho), os quais foram cultivados em placas de Petri com meio de cultura $\mathrm{BDA}$, onde comprovaram que apenas as bactérias do gênero Bacillus sp. foram capazes de controlar o desenvolvimento da M. phaseolina. VillelaMarroni (2015), também com trabalho conduzido in vitro em laboratório, avaliou a eficiência de 19 isolados da bactéria Bacillus sp. no controle do fungo de solo $M$. phaseolina, onde concluiu a eficácia do Bacillus como antagonista do fungo fitopatogênico, apresentando grande potencial de proteção e como agente de controle biológico para a M. phaseolina.

Menezes et al. (2004), avaliando em vasos o efeito de isolados de fungo do gênero Trichoderma tanto no tratamento de sementes de feijão sobre o patógeno M. phaseolina presentes no solo, como no tratamento de solo sobre o patógeno presente em sementes de feijão, evidenciou como resultado a maior conservação das plantas de feijão quando o patógeno foi aplicado no solo esterilizado e tratado com o Trichoderma antes do plantio, com uma suspensão contendo conídios do bioprotetor. Ainda que a totalidade das espécies de Trichoderma avaliadas no trabalho se mostraram com resultados promissores, o controle da M. phaseolina apresentou maior resultado na supressão da doença com a utilização de $T$. haržianum em todos os experimentos executados.

Em geral, o controle biológico parte do princípio do antagonismo entre microrganismos, podendo ser eles a competição, o parasitismo, a predação e a indução de resistência. A inibição de fitopatógenos por muitos microrganismos ocorrem por competição de nutrientes, pela produção de metabólito e através do parasitismo direto, onde podem operar de 
maneira só ou conjunta. A competição se dá pela relação entre dois ou mais organismos comprometidos na mesma ação, acontecendo em especial por espaço, alimentos e oxigênio. No parasitismo, o fato ocorrido é através da nutrição de certo microrganismo a partir de estruturas reprodutivas ou/e vegetativas de outro microrganismo. Já na predação, o microrganismo se alimenta de fitopatógenos e de múltiplas fontes. A indução de resistência acontece com estímulos os dispositivos de defesa do hospedeiro através da inserção da estrutura não deletéria ou/e de seus metabólitos (FRANCA, 2020).

Ao agirem sobre o agente patogênico, as rizobactérias produzem bacteriocinas, ácido cianídrico, antibióticos, enzimas líticas, sideróforos e ainda acabam por induzirem resistência sistêmica. A atuação na supressão de doenças é indireta e seu uso no aumento de rendimento e como bioprotetores, será certamente, uma das técnicas para alta produtividade de maior valor nesse século, tudo isso devido à crescente demanda da redução da compulsão por produtos químicos sintéticos e a primordialidade de desenvolvimento da agricultura sustentável (MARCUZZO, 2011).

\section{CONCLUSÃO}

De acordo com os resultados obtidos, a utilização dos bioagentes Bacillus sp. e Trichoderma haræiianum se mostraram eficientes na supressão da Macrophomina phaseolina na cultura do feijoeiro comum, quando aplicado em tratamento de sementes e em pulverização foliar. Com as mesmas aplicações, a utilização de Pseudomonas fluorescens e o Bacillus sp. são eficientes na promoção de crescimento de biomassa de parte aérea. A integração da utilização destes microrganismos na produção agrícola contribui para uma produção sustentável, além de redução de custos e tempo de investimento, reduzindo também a utilização de produtos químicos. É necessário a realização de mais estudos para identificação de biocontroladores do fungo $M$. phaseolina com capacidade antifúngica, em especial com estudos em condição de campo.

\section{REFERÊNCIAS}

ABAWI, G.S.; PASTOR-CORRALES, M.A. Root rots of beans in Latin America and Africa: diagnoses, research methodologies and management strategies. Colômbia. CIAT. 1990.

ADAMSKI, A. Avaliação de cultivares de feijão quanto à qualidade tecnológica de grãos. Universidade Federal da Fronteira Sul. 2019.

ARAÚJO, F. F. de; ARAÚJO, A. S. F. de; SOUZA, M. R. de. Inoculação do feijão-caupi com rizobactérias promotoras de crescimento e desempenho na produção de biomassa. Pesquisa Agropecuária Pernambucana. 17 (1), 53-58. 2012. Disponível em: https://doi.org/10.12661/pap.2012.010

ATHAYDE SOBRINHO, C. Patossistema caupi X Macrophomina phaseolina: método de detecção em sementes, esporulação e controle do patógeno. Tese. Universidade de São Paulo. 2004.

BARBOSA, A. F. S.; SILVEIRA, L. A.; LEAL, P. L. Caracterização de rizobactérias associadas à melocactus conoideus quanto a mecanismos de promoção de crescimento de plantas. Revista Ciência e Desenvolvimento. 10.3: 328-345. 2017.

CAMPBELL, C. L.; MADDEN, L. V. Introduction to plant disease epidemiology. New York NY. John Wiley \& Sons. 1990.

CERQUEIRA, W. F.; MORAIS, J. S.; MIRANDA, J. S.; MELLO, I. K. S.; SANTOS, A. F. J. Influência de bactérias do gênero Bacillus sobre o crescimento do feijão comum (Phaseolus vulgaris L.). Enciclopédia Biosfera. Centro Científico Conhecer. Goiânia-Go. v.11, n.20: p.82. 2015.

CONAB. Acompanhamento da safra brasileira grãos. V. 7 - SAFRA 2019/20 - N. 6 - Sexto levantamento. Março, 2020a.

COSTAMILAN, L. M.; TOMM, G. O.; CLEBSCH, C. C.; KIIHL, T. A. M.; DENARDIN, N. Avaliação de resistência de canola à Podridão Negra das Crucíferas. In Embrapa Trigo-Artigo 
em anais de congresso (ALICE). In:

SIMPÓSIO BRASILEIRO DE CANOLA, 1 ., Passo Fundo. Anais... Brasilia, DF: Embrapa, 2017.

CROUS, P. W.; SLIPPERS, B.; WINGFIELD, M. J.; RHEEDER, J.; MARASAS, W. F.O.; PHILIPS, A. J. L.; ALVES, A.; BURGESS, T.; BARBER, P.; GROENEWALD, J. Z. Phylogenetic lineages in the Botryosphaeriaceae. Studies in Mycology, v. 55, p. 235-253, 2006.

DIAS, L. R. C.; SANTOS, A. R. B.; PAZ FILHO, E. R.; ATHAYDE SOBRINHO, C. Oleo essencial de Lippia sidoides Cham (alecrim-pimenta) no controle de Macrophomina phaseolina em feijãocaupi. Revista Cubana de Plantas Medicinales, v. 24, n. 1, 2019.

FERREIRA, D. dos S. A. Eficiência de Bacillus amyloliquefaciens na promoção de crescimento e produtividade do milho. Trabalho de Conclusão de Curso (Graduação em Agronomia) Universidade Federal de Mato Grosso. Instituto de Ciências Agrárias e Ambientais. Sinop. 35f. 2018a.

FERREIRA, T. C. Bacillus spp. como agentes de controle de Thielaviopsis paradoxa e Fusarium verticillioides e promotores de crescimento de cana-de-açúcar e milho. Tese de Doutorado. Unesp Câmpus de Botucatu. 2018b.

FILIPPI, M. C. C.; SILVA, G. B.; SILVA-LOBO, V. L.; CÔRTES, M. V. C. B.; MORAES, A. J. G.; PRABHU, A. S. Leaf blast (Magnaporthe oryzae) suppression and growth promotion by rhizobacteria on aerobic rice in Brazil. Biological Control. 2011. Disponivel em: https://doi.org/10.1016/j.biocontrol.2011.04.0 16

FRANCA, A. C. A. Controle biológico da Antracnose na cultura do feijão-vagem com o uso de bioagentes. Trabalho de Conclusão de Curso. Bacharelado em Agronomia. Anápolis-GO. 2020.

KADO, C.I.; HESKETT, M.G. Selective media for isolation of Agrobacterium, Corynebacterium, Ervinia, Pseudomonas and Xanthomonas. Phytopathology 60:969-979. 1970.

MAPA. Ministério da Agricultura, Pecuária e Abastecimento. Brasília. Disponível em: http://www.agricultura.gov.br. Acesso em 04 de mar. 2020.
MARCUZZO, L. L. Efeito de rizobactérias sobre o biocontrole e promoção de crescimento de plantas. Ágora: Revista De divulgação científica, 17(1), p. 1-11. 2011. Disponível em: https://doi.org/10.24302/agora.v17i1.16

MARTINS, M. F. Avaliação da resistência de linhagens de feijoeiro ao Nematoide Meloidogyne javanica e ao fungo Fusarium oxysporum f. sp. phaseoli. Master's Thesis. 2015.

MENEZES, M.; MACHADO, A. L. M.; SILVEIRA, M. do C. V. da; SILVA, R. L. X. da. Biocontrole de Macrophomina phaseolina com espécies de Trichoderma aplicadas no tratamento de sementes de feijão e no solo. Anais da Academia Pernambucana de Ciência Agronômica. Recife. vol. 1, p.133-140, 2004.

PAULA JÚNIOR, T.J. de; VIEIRA, R.F; TEIXEIRA, H. et al. Informações técnicas para cultivo do feijoeiro-comum na região central brasileira 2007-2009. Belo Horizonte: Epamig, 180p. (Epamig. Documentos, 42), 2008.

SÁ, M. N. F. Microbiolização na qualidade de sementes e crescimento de plantas de feijãocaupi. Trabalho de Conclusão de Curso (Bacharelado em Agronomia). Instituto Federal de Educação, Ciência e Tecnologia do Sertão Pernambucano. Campus Petrolina Zona Rural. Petrolina-PE. 2019.

SILVA, H. T.; COSTA, A. O. Caracterização botânica de espécies silvestres do gênero Phaseolus $L$. (Leguminosae). Embrapa Arroz e Feijão. Documentos 156. 2003.

SILVA, A. R.; SILVA, M. R.; DELAMUTA, J. R. M.; SANTOS, J. A.; RIBEIRO, R. A.; BINNECK, E.; ALMEIDA, A. M. R. Identificação e eficiência de Bacillus spp. inibidor do crescimento de Macrophomina phaseolina. In Embrapa Soja-Artigo em anais de congresso (ALICE). In: JORNADA ACADÊMICA DA EMBRAPA SOJA, 8., Londrina. Resumos expandidos. Londrina: Embrapa Soja, p. 4245.2013 .

TESSO, T.; EJETA, G. Stalk strength and reaction to infection by Macrophomina phaseolina of brown midrib maize (Zea mays) and sorghum (Sorghum bicolor). Field Crops Research. Estados Unidos, v.120, p.271-275, 2011.

VAZ, F. N. Desempenho agronômico de genótipos de feijoeiro comum do grupo carioca normal, nas 
águas, em Uberlândia-MG. Uberlândia. Minas

Gerais. 2020. Disponível em:

http://orcid.org/0000-0002-6662-9544

VIEIRA, B. S.; VIEIRA, H. M. P.; SOUSA, L. A.; DE MENDONÇA, K. D. R. Potencial

antagonístico do isolado bacteriano (bsv-05) contra os patógenos radiculares do feijoeiro: Fusarium solani f. sp. phaseoli, Fusarium oxysporum $f$. sp. phaseoli, Macrophomina phaseolina e Rhizoctonia solani. Revista Ciência Agrícola, 14(1), 59-66.

2016. Disponível em:

http://dx.doi.org/10.28998/rca.v14i1.2333.

VILLELA-MARRONI, I. Triagem de bactérias do gênero Bacillus para o controle do fungo fitopatogênico Macrophomina phaseolina. Biocontrol Science and Technology, 25 (3): 302-315, 2015. 